\title{
Challenges and Opportunities of Crowdsourcing and Participatory Planning in Developing Infrastructure Systems of Smart Cities
}

\author{
Parul Srivastava ${ }^{1}$ and Ali Mostafavi ${ }^{2, *}$ (1) \\ 1 Department of Civil Engineering, Indian Institute of Technology, Kanpur 208016, India; parulsri@iitk.ac.in \\ 2 Zachry Department of Civil Engineering, Texas A\&M University, College Station, TX 77843, USA \\ * Correspondence: amostafavi@civil.tamu.edu; Tel.: +1-765-543-4036
}

Received: 12 October 2018; Accepted: 10 November 2018; Published: 14 November 2018

\begin{abstract}
The concept of Smart City aims to provide its citizens with infrastructure systems that make cities safer and more livable. One of the methods for doing so is collecting data from the crowd itself-termed crowdsourcing - and incorporating their ideas to improve the existing facilities, as well as build new ones to cater to their arising needs. This paper aims to inspect the attributes that govern crowdsourcing, evaluating its feasibility in attaining solutions in the present scenario. A systemic review of the existing literature on crowdsourcing platforms was conducted and major findings have been summarized adequately. The areas of environment, disaster management, public safety, innovation, transportation and health have been explored in connection to the existing crowdsourcing platforms and selected examples have been mentioned. Next, the attributes that affect crowdsourcing have been discussed in detail under three broad categories: (1) human characteristics; (2) data characteristics and (3) system characteristics. In the end, some recommendations for improvement in the implementation of the crowdsourcing platforms have been proposed for their enhanced applicability and effectiveness.
\end{abstract}

Keywords: crowdsourcing; participatory planning; smart city; infrastructure systems; attributes; challenges; human; data and system characteristics

\section{Introduction}

The ever-growing population of the world is an emerging concern for the sustenance of humanity. A recent trend of shifting of populations from rural areas to urban areas, known as urbanization, poses numerous challenges to the public. On one hand, urbanization provides people with immense opportunities of growth and development, however, the difficulties faced by the people in these urban areas are also numerous. These include congestion in transport, competition for health care services, pollution, scarcity of non-renewable resources, management of solid waste, lack of educational opportunities and safety concerns of citizens. Also, the government may encounter problems with effective public administration to cater to the needs of such a huge population of urban areas with diverse people and their sundry needs. There are projections of about $61 \%$ of the world's population to be living in urban areas by 2030 [1]. This only puts more pressure on the present infrastructure systems as they become less capable of dealing with the existing and yet-to-be-born challenges. In order to mitigate these problems, the cities need to be not only sustainable but also intelligent. This puts in perspective the much-discussed concept of Smart Cities with Intelligent Infrastructure Systems. Smart cities aim to provide better services to its residents keeping in mind their ease of use and accessibility. One of the ways to do so is by integrating inputs from the citizens through crowdsourcing platforms, with the infrastructure systems. Smart cities also strive for encouraging people's participation in 
planning of the functioning of these systems, to provide smart solutions to the problems they face in everyday life.

Despite crowdsourcing being the state-of-the-art of the present century, a deep understanding of the challenges and opportunities it comes with, with respect to incorporation in smart infrastructure systems, is yet not completely explored. This paper aims to identify and study the attributes of these crowdsourcing application platforms and presenting a holistic view of the crowdsourcing process in front of the readers. The attributes refer to the factors that affect the efficient functioning of the crowdsourcing platforms. The intent is to study each attribute and present it as an advantage as well as a limitation and recommend ways of incorporating those attributes in crowdsourcing for urban infrastructure development. The objective of the paper is also to study the interdependence of attributes and identify how these interactions add to the success or failure of a crowdsourcing initiative. These aims shall be achieved by systematic review of existing literature and by identifying gaps in the idea they collectively put forward. Attempts have also been made to fill the gaps with our own interpretations to draw a full picture of the present-day scenario of the crowdsourcing application platforms.

In this study, a comprehensive review of existing literature on smart city infrastructure systems was conducted to gain insight into the demand of intelligent infrastructure systems of smart cities. A brief introduction to the concepts related to smart cities, crowdsourcing and participatory planning has been presented in the theoretical framework. Next, some existing crowdsourcing applications in the fields of environment, disaster management, public safety, ideas and innovation, transportation and health are discussed. The section on materials and methods presents the methodology adopted for summarization of information from the relevant literature relating to crowdsourcing, its challenges and attributes. The discussion on attributes of crowdsourcing has been divided into three categories: (1) human characteristics; (2) data characteristics and (3) system characteristics. For each characteristic, the challenges and recommendations for its implementation in urban infrastructure systems have been discussed. Next, the recommendations to overcome the challenges posed by these attributes collectively, have been mentioned. The concluding remarks summarize the major findings of the paper and the possible impact it hopes to achieve. This study has attempted to cover all the challenges and opportunities in crowdsourcing platforms as mentioned in the literature but the comprehensiveness of the attributes may extend beyond the scope of this paper. The focus of this study is, therefore, on the challenges associated with each attribute and the recommendations to overcome them.

\section{Theoretical Framework}

The definition of smart cities has evolved over a period of time. Albino et al. [2] discuss that the smart city is defined in different ways by researchers and there is not a uniform template for its definition. They suggest that the concept of a smart city is majorly focused on sustainability and needs of its people and community and does not necessarily relate to the diffusion of Information and Communication Technology (ICT). However, in this study, citizens and technology have been considered as the primary drivers of a smart city.

Smart city aims to make cities safe, sustainable, inclusive, user-friendly and demonstrative, as described in Figure 1 [3]. The safety of citizens includes their privacy protection on online platforms, safety from accidents and prevention of crimes. The criterion of sustainability encompasses the fields of environment, economy, governance and society. The inclusiveness vision targets the removal of any bias in access to digital services due to diversity in income, race, age and gender. The services provided by the smart cities should be easily accessible and easy to use. Digitals platforms created should empower residents by expanding civic engagement in collection of data and decision-making. Lastly, the city can provide a platform to innovators and start-ups which will create new impactful and transformative technologies that will have an everlasting effect on the way people live. 
Nam and Pardo [4] discuss the three dimensions of a smart city-technology, people and community and the three factors they depend on, that are technological factors, human factors and institutional factors, respectively.

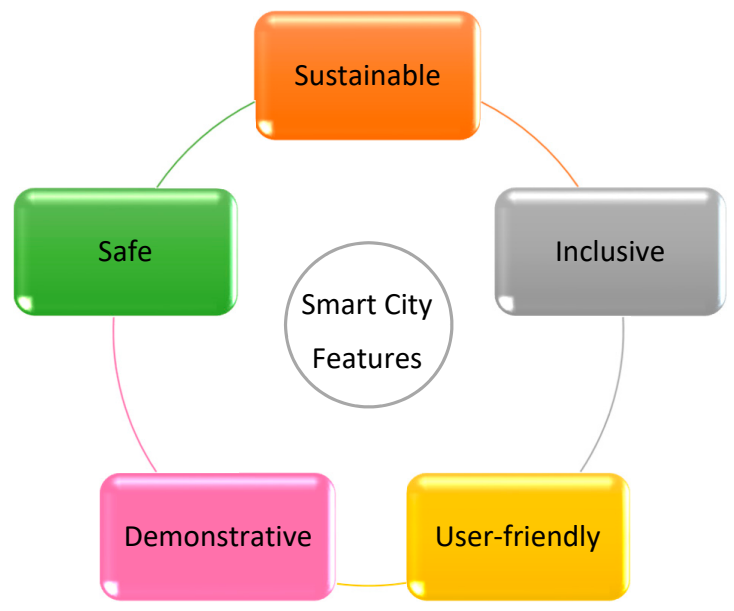

Figure 1. Features of Smart City Vision.

The dimension of technology covers the range of digital city, intelligent city, virtual city, ubiquitous city, wired city, hybrid city and information city. The latest vision of smart cities is to use digital technology to deliver services and respond to the needs of the citizens in real time. The leaders of smart cities want to follow an inclusive approach to solving problems of daily life. The focus is to solve the "real problems of real people" [5]. The underlying idea of embedding technology in societal functioning is what makes the infrastructure system "intelligent." Intelligent here signifies not the inclusion of computer machinery to solve problems objectively but a people-centered technology that is run by the people and caters to their needs too. Smart City as an urban development model aims to integrate human and technological inputs collectively to enhance the development and well-being of urban settlements [6]. The technological factors on which smart city depends include: wireless infrastructure [7], network equipment (fiber optic channels and Wi-Fi networks), public access points (kiosks, wireless hotspots) and service oriented information systems [8]. These components are vital for the establishment of the technological infrastructure in any smart city.

The second dimension that Nam and Pardo [4] talk about is people. The concepts of creative city, learning city, humane city and knowledge city fall under this category. Smart people are an important ingredient of a smart city. The participation of citizens in developing new infrastructure systems is an integral part of the smart city initiative. Citizens act as democratic participants, co-creators and ICT users [9]. Education plays an important role in this. The intelligence of a smart city is facilitated by the collective intelligence and social learning of its citizens [10]. People come forward to provide smart solutions to their own problems by means of their creativity, cooperation and ideas [11]. To agglomerate human contributions for problems solving, inputs are needed from digital citizens. The term 'Crowdsourcing' first mentioned by Howe [12], also known as 'First Generation Crowdsourcing,' is essentially inviting the crowd to generate ideas, to complete pre-defined tasks and to propose solutions. Prpic [13] discusses crowdsensing, situated crowdsourcing, spatial crowdsourcing and wearables crowdsourcing as the representation of a paradigm shift in data collection and decision-making and calls it 'Next Generation Crowdsourcing.' It means that it is not necessary for citizens to actively participate in data collection. By using sensors, working on Global Positioning Systems (GPS) technology, built into smartphones and certain apparels or accessories, data can be collected autonomously and with much ease through the passive participation of citizens. This has been termed as Volunteered Geographic Information (VGI) by Goodchild [14]. VGI has been defined as "the widespread engagement of large numbers of private citizens, often with little formal qualifications, in the creation of geographic information". Such a way of data collection would lead 
to better understanding of patterns of usage of services by citizens. A better knowledge of citizens' needs will help the agencies to provide better services to citizens. Existing examples of sensors are the ones used for monitoring air quality. Vehicle-based sensors can check conditions of the roads using installed accelerometers and also monitor traffic using GPS technology. Sensors in smartphones can help build new street maps, by uploading the path one took to go from one place to another.

The third dimension is the community [4]. The institutional factors on which this dimension depends is governance, policy and regulations made by it. IBM [15] states that smart government is a key component of a smart city. It is important for the political parties in power to reach conscious and agreed-upon decisions for the smart growth of cities [16,17]. 'Participatory Planning' denotes citizens' involvement in the planning and decision-making process of a city. Traditional planning approaches include conduction of public gatherings, public surveys and consensus conferences and taking inputs from public advisory committees in which to give one's opinion physical presence of a citizen is mandatory [18]. Brabham et al. [19] state that such a traditional public participation approach can never be representative of the whole community. Needs of the underserved society can never catch attention in such meetings. Also, it is a huge challenge to decide the date, time and place of such meetings which inhibit employed people and senior citizens from attending such gatherings. Thus, it is beneficial to incorporate the ICT in the planning procedure to reap the benefits of e-participation. Mobile participation or m-participation applications are the latest form of e-participation and eliminate the barriers of physical presence for getting heard [18]. Bonabeau terms this paradigm shift in the decision making process, through an amalgamation of social networks, collaborative software and other Web-based tools, as "Decision 2.0" [20]. Another form of participatory planning can be through Participatory GIS (PGIS) and Public Participation GIS (PPGIS) based applications [21]. The citizens can enter their opinion on a planning topic and mark it on a map in a geospatial layer. Participatory Planning aims to harmonize the interests and ideas of diverse groups and aspires to remove the conflicts among opposition parties. The solution reached upon, through participatory planning, fulfils the desires of a large section of the society without treating the views of others with disdain. An emerging concept in the field of participatory platforms is the City-as-a-platform [22] and living labs [23]. Such platforms provide an environment where users and the agencies can co-create innovations. They are primer to shaping the future of a smart city by collective contributions. Such an approach to planning is congenial with the inclusive vision of smart city planners.

Encalada et al. [24], through the example of a tourism application, show that the successful implementation of crowdsourcing and participatory planning involves immense amounts of data collection, processing, storage and retrieval. To do this, extensive algorithms are required at each step. Tenney and Sieber [25] describe the realm of data-driven participation that employs big data analytics, and how algorithms act behind the scene as the primary control. Also, these algorithms act in real-time, learning from existing observations to improve their own database and predictive capabilities [26]. The inclusion of enormous data and artificial intelligence in algorithms in crowdsourcing also poses numerous challenges. Arroub et al. [27] identify the major challenges to be the huge amount of data being generated and its reliability, security and privacy issues and the standardization of laws to make the applications, using crowdsourcing as a tool, more trustworthy. Degbelo et al. [28] also describe the challenges with a major focus on citizens. Such challenges make it hard for a smart city to fulfil its goals of ensuring security, user-friendliness and sustainability and interferes with its smooth functioning. Thus, it is extremely important to investigate the challenges faced by the users as well as the agencies obtaining information from these crowdsourcing platforms, in terms of people involved, the activity for which crowdsourcing is undertaken and the data that is being generated and come up with ways in which these challenges can be overcome. The next section takes a look at the existing applications employing crowdsourcing in various fields of infrastructure to better understand the process of crowdsourcing. 


\section{Major Areas of Application of Crowdsourcing}

Smart city solutions have already been implemented in many parts of the world and there have been many success stories as well as lessons to be learnt from some challenging obstacles faced in their implementation. The core infrastructure elements of a smart city include electricity, water, energy, sanitation, housing, education, transport, Information Technology (IT) connectivity, health and safety. It also targets improvement of the resilience of these infrastructure systems in case of emergencies. The following section discusses some of the existing smart city applications in some fields as mentioned in Figure 2. The applications that make use of crowdsourcing to collect data in these fields have also been summarized in Table 1.

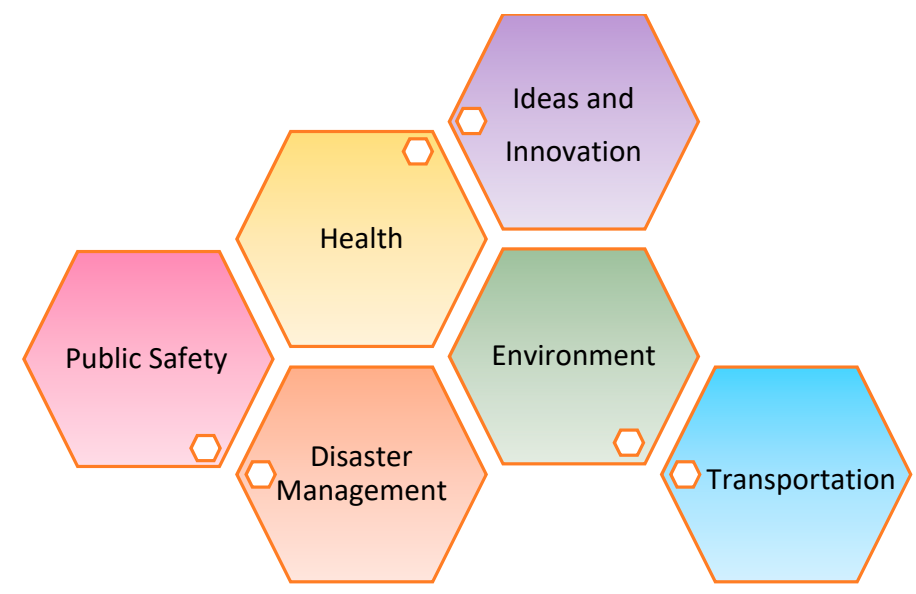

Figure 2. Areas of application of crowdsourcing in the context of smart city planning.

\subsection{Environment}

Latest technologies help provide citizens with better facilities and a cleaner environment to live in. Crowdsourcing can be used to monitor environmental quality through handheld or wearable gadgets and sensor devices. Environment monitoring stations need to be set up that collect air quality samples in real time. In this way, the source and movement of polluting fumes can be tracked and citizens can be warned. Many handheld devices and wearables with inbuilt GPS technology can also be used to test the air and water quality. From the information recorded, a real-time map of variation in environment quality at different places can be easily created. In Beijing, people use PiMi Airbox, a low-cost air quality monitor to create a crowdsourced map of indoor air pollution. The data collected can then be used for generating a warning system for people suffering with respiratory diseases and this data can be integrated with health issues data to know the source of pollution and the damage it is causing.

Smart waste collection bins [29] collect waste oils, textiles, recyclables, plastic and general waste in different bins. Smart bins come with sensors that provide information on the container fill levels, geopositioning, temperature and so forth. This information can be easily accessed through an online platform and thus waste collection by municipalities can be optimized in terms of cost, time and labor.

In concordance with the smart city vision of sustainability, there is a rising trend of sharing, renting, buying and selling things among people in the form of services. OLX, eBay, Billiji, BlockPooling are some apps that allow people to share or sell things they rarely use. This reduces amount of waste production and thus, helps keep environment clean.

\subsection{Disaster Management}

Learning from the successful examples of Ushahidi [30] and OpenStreetMap [31], crowdsourcing proves to be an effective tool for relief efforts during times of disaster. Real-time mapping of flood or earthquake damage can be done using a combination of crowdsourced data and satellite imagery by overlapping the two to create maps representative of the effects of the disaster. Recently, Google 
launched an application called Person Finder [32] for Kerala floods in India where people can report if they have information about someone or if they are looking for someone. Ref. [33] lists the advantages of using crowdsourcing for disaster relief. The data about the level of damage and seriousness of the case is almost immediately collected after the disaster. Also, using the techniques of data filtering, sorting and pattern identification, the relief requests can be prioritized and most crucial need for medical help, food, shelter can be addressed first. The inclusion of GPS information makes it easier to locate the people wanting help.

Also, highly efficient warning systems can be built by the mapping of disaster in real time. This can help in evacuation measures and disaster preparedness on the part of both citizens and government. An example of real-time mapping of flooding in Jakarta is their platform PetaJakarta. The map is created by crowdsourcing flood reports from Twitter.

\subsection{Public Safety}

Several applications have been developed that focus on the issue of public safety against crime. They map out the crime activity, rate of crime in a locality and the best and worst time of days one can visit the place. The information about crime can be gathered through the reported news, or people themselves can report any sort of mishap they have faced. The application could also serve to connect victims to police or to fellow residents so that help can be provided as soon as possible and crimes can be prevented. Hawk Eye is one such global crime reporting application for mobile phones that allows citizens to report crimes and call for help, ensuring their safety while travelling.

The latest feature launched by Ola Cabs in India is a SOS icon on top of the application. This can be touched, if the rider is in danger and the emergency contacts as well as the company will be notified of the location of the rider, driver details and so forth. Similar ways of data collection can help in ensuring the safety of riders, especially women travelling alone and help in making cities safer to live in.

\subsection{Ideas and Innovation}

Involving the citizens in the planning process of the city is crucial. Many cities have already started to consider taking the opinion of citizens in almost every field. In France, Madam Mayor I have an idea is a platform for online submission of ideas in budget allocation on infrastructure in the city. In Reykjavik, Better Reykjavik platform can be used to submit ideas on almost any common topic online. Better Reykjavik is built on Your Priorities platform which enables people to develop, prioritize and decide on ideas to be implemented in the city.

\subsection{Transportation Infrastructure}

Maintenance of civil infrastructure to keep it functioning well lies at the core of smart city planning. The best thing is that crowdsourcing can be put to its optimum use for obtaining the information for maintenance. Anything that needs to be maintained can easily be reported in the form of a photo and it will get fixed by the authorities. FixMyStreet and Street Bump applications work on a similar philosophy. People can upload the photo of any problem in the street and after that information has been verified, officials are sent to repair the road. Street Bump detects the presence of pot holes and bumps on the road by use of sensors. This information is automatically collected and routed to the authorities for proper action.

Smart street lighting uses the sensor technology to detect the presence of vehicles or pedestrians and light up when someone passes by and remain off when there is no activity detected. Such a way of lighting the streets would be both energy and cost efficient.

Every parking space can be installed with sensor to detect whether the parking space is vacant or occupied. It can then be linked with an online platform so that people can search for empty parking lots. This will save both time and money and finding parking would be much easier.

Strawberry Tree [34] is a solar energy operated smart-city platform which provides mobile charging ports, free Wi-Fi connectivity and environment sensing. Another service based on the same idea is 
Soofa [35], which provides free charging for mobile phones and operates on solar power. This kind of a technology would help in saving energy and providing sustainable services to citizens.

Carpooling applications like SoCar, Poolmyride, Sidecar, OlaShare and Rideshare allow the riders of the same route to share cars while travelling. Platforms like Bike Share and Ola Cycle allow citizens to rent a bike and then return it to a designated stand and leave it locked for the next user who can easily rent it by entering a digitalized code for the bike.

\subsection{Health}

The field of health has made a great progression through both the active and passive participation of people. Information about health monitoring, disease protection, vaccination and epidemic breakout is available at one click. In November 2008, Google Flu Trends was able to map the outbreak of influenza using the Google search data of people and predict the spread of disease and response of people in near real time [36,37]. Other similar disease-mapping and prediction platforms are GermTrax [38], which works on data collected from individuals, and Sickweather [39] that collects data from both social networking websites as well as from direct crowdsourcing. CrowdMed [40] is an online website that integrates the ideas of patients, practitioners and the general crowd for the diagnosis and treatment of diseases. It works in a three-fold step. First, the patient submits a case, then medical detectives comprising of doctors, other patients and people provide the patient with advice based on their knowledge and experience. A final report is submitted to the patient based on the top solutions which he can take to his physician for helping in proper treatment.

Thinking of an idea and making an application on it is the easier part of the smart city initiative. The real problem begins when these applications are used and difficulties are encountered in the implementation phase of the platform. In order to realize the idea of digital incorporation in crowdsourcing and city planning, there is a compelling need to fully understand the peculiarity of this process. This is required for optimizing the management of resources of such systems and to maximize the efficiency of services they provide. Existing platforms for crowdsourcing data have been developed with little knowledge about the behavior of citizens involved and the characteristics of data collected. One of the major shortcomings is that the concept of digitalization of existence advocates the presumption that the citizens have access to technology, possess the skills to use it and the willingness to participate in these platforms and make contributions [41]. This may not always be true as many places still do not have access to the internet. Security threat detection and handling is another major challenge that crowdsourcing platforms face. The people will be motivated to engage themselves only when they feel that their privacy will not be breached and their information will be secure. Also, trusting the data-collecting mobile-based sensing devices to be accurate for providing a reliable data and not considering the errors that can be made by humans in providing solutions, is also a leading issue in successful employment of crowdsourcing for public utility. Another key question that leads us here is the competence of presumed amateur crowd with the professionals for providing solutions to the client on such platforms or may be questioning whether this presumption is valid or not. The above-mentioned characteristics of human, system and data cause unforeseen challenges to emerge which are difficult to handle and any effort to combat it is futile once an irreparable harm is done.

Table 1. Examples of popular crowdsourcing platforms according to fields of their application.

\begin{tabular}{cc}
\hline Field of Application & Examples \\
\hline Environment & PiMi Airbox (air quality monitor) \\
Disaster Management & OLX, eBay, Billiji, BlockPooling (promote reuse of products) \\
Public Safety & Ushahidi, OpenStreetMap, Google Person Finder, PetaJakarta \\
Idea and Innovation & Ola Cabs (SOS button), Hawk Eye \\
Transport & Madam Mayor I have an idea, Better Reykjavik \\
Health & FixMyStreet, Street Bump \\
& Carpooling Applications: SoCar, Poolmyride, Sidecar, OlaShare, Rideshare \\
\hline
\end{tabular}




\section{Methodology}

Firstly, suitable literature was identified to gain insight into the modern vision of smart cities and demand for intelligent infrastructure systems to make cities smart. A detailed study was conducted to understand the link between smart cities, crowdsourcing and participatory planning. A study of the existing smart city solutions was done and segregated according the field of infrastructure they cater to, some of which have been discussed in the previous section. This was done to evaluate the processes that are employed in any crowdsourcing platform and later, identify the challenges in each of them. Since the focus of the paper is only on the challenges and opportunities of crowdsourcing, the literature was now focused only on these two. Therefore, literature on challenges faced by existing crowdsourcing platforms was reviewed and specific attributes were identified. There were more than one hundred scholarly articles, government brochures, smart city proposals and company journals identified for a primary review. These articles and reports were published predominantly between 2003 and 2016. All these articles were organized in the form of a repository and then segregated according to the specific concepts each of them covered. Since the information in many research articles was overlapping and sometimes, one article addressed more than one attribute, 36 articles were shortlisted for addressing specific attributes in entirety.

Figure 3 shows the research guideline which was used to code and process information from the state-of-the-art practice. The research framework regulating the compilation of this paper is presented in Figure 4. The paper is divided into two broad discussions-the challenges faced by the clients and the users of the crowdsourcing platforms in terms of attributes that govern their working and the opportunities, in terms of recommendations for improvement in attributes, to further expand the use of crowdsourcing to optimize the benefits to the society as a whole. Figure 5 depicts the distribution of existing literature all over the world. It is noteworthy that the major studies have been carried out in parts of Europe and North America. This indicates that in developing countries, crowdsourcing is still in its budding stage and not much research has been conducted there. Figure 6 suggests that most of the articles published in this research area happen to be in the 21st century, mainly after 2010. Therefore, crowdsourcing is a relatively novel phenomena and still needs to be understood in its totality. Figure 7 enlists the distribution of literature according to the attributes they address. This also hints at the relative importance of one attribute over the other. Transparency in data, privacy issues, motivation for crowdsourcing, digital divide and reliability of data emerge as the primary concerns while assessing the feasibility of crowdsourcing. Some of the attributes were not specifically found in literature and have been introduced.
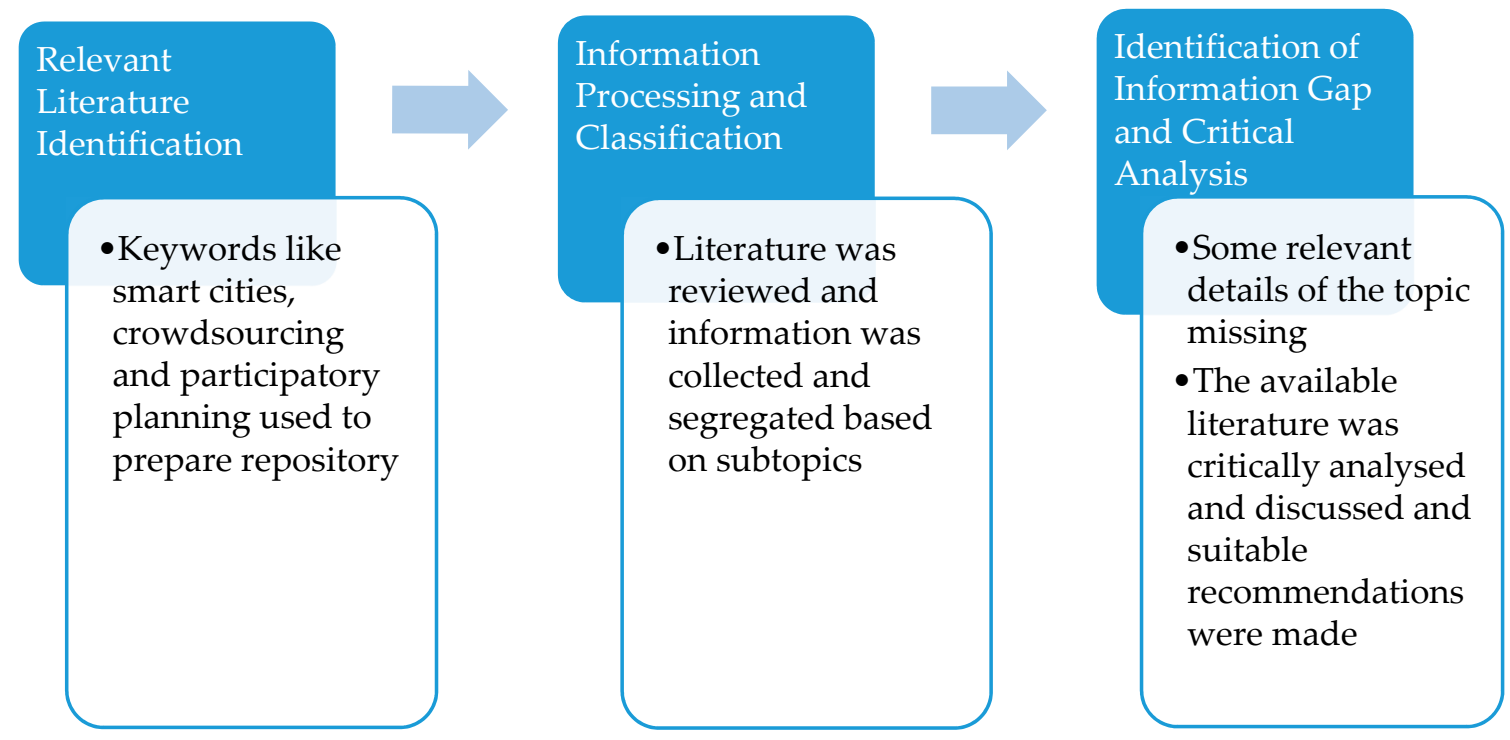

Figure 3. Research guideline: literature review, information processing and analysis. 


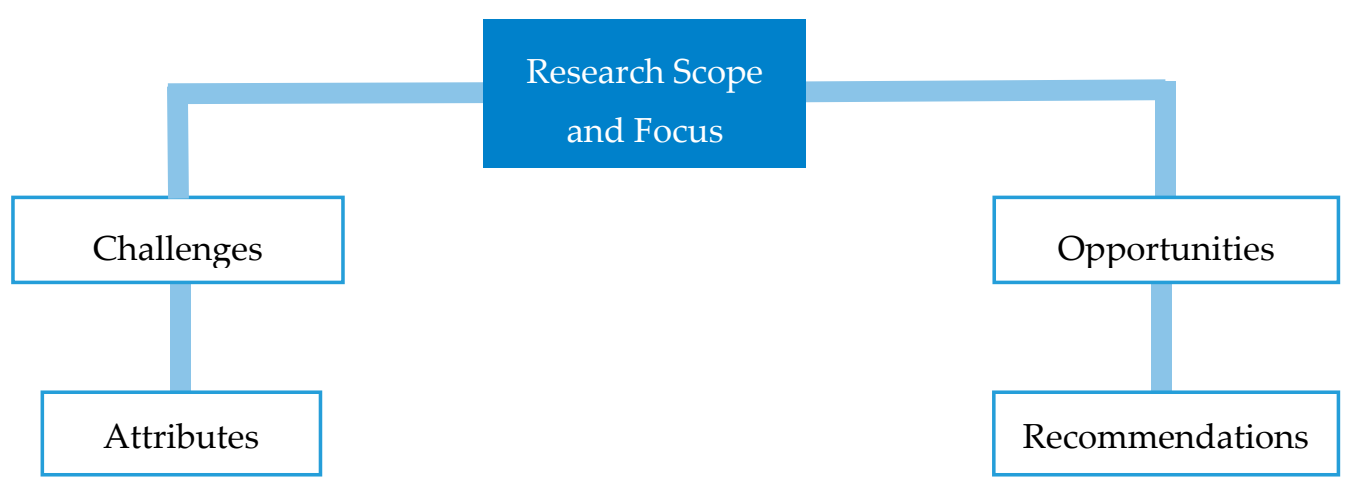

Figure 4. Research framework.

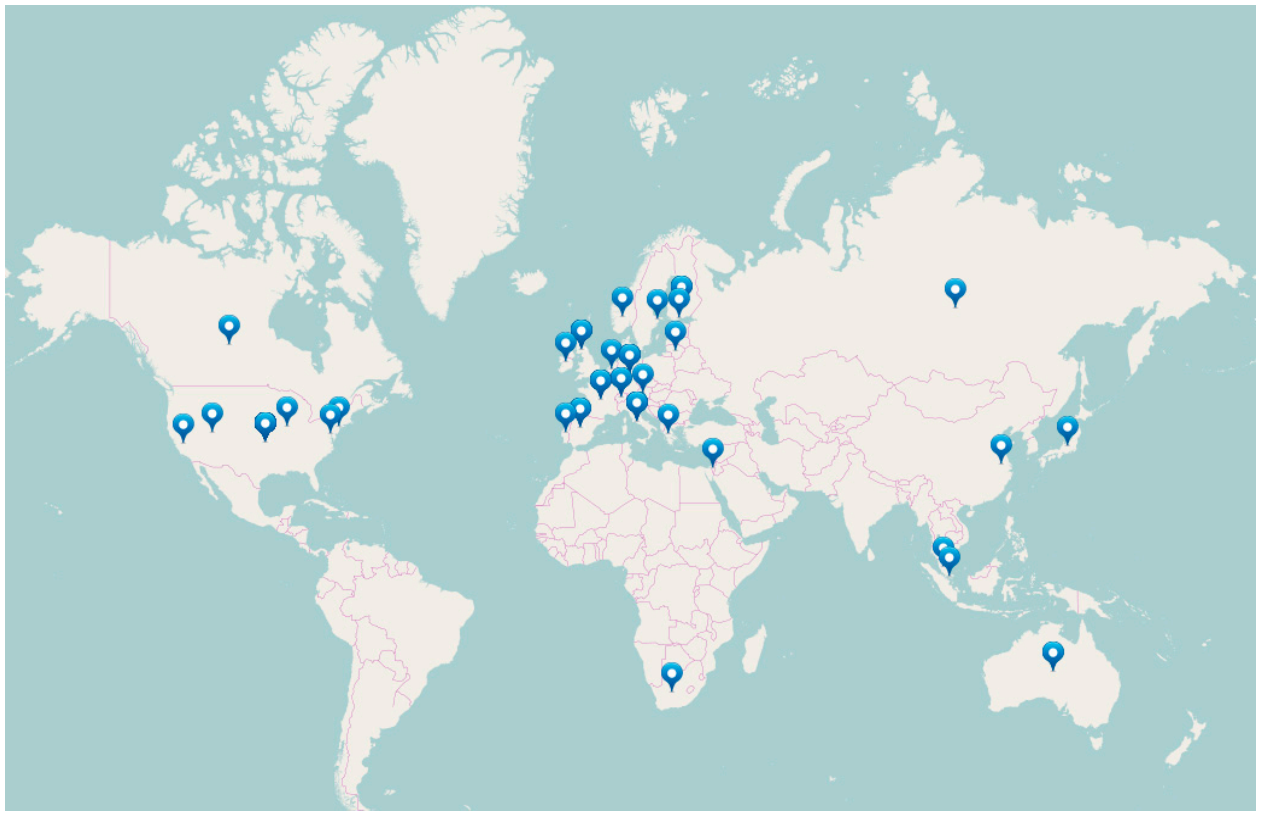

Figure 5. Distribution of literature all around the world.

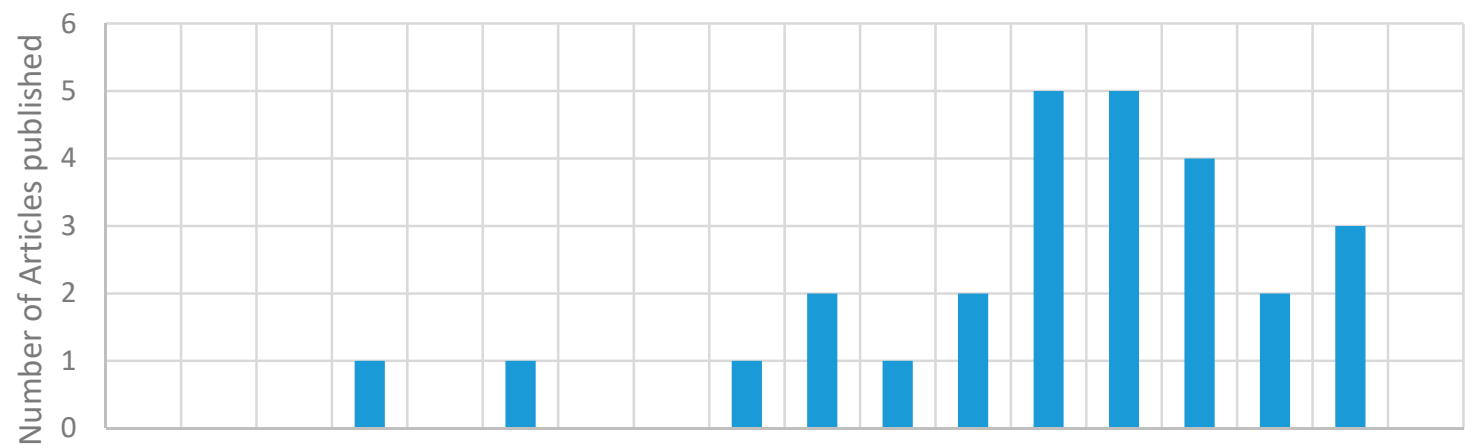

20002001200220032004200520062007200820092010201120122013201420152016

Year

Figure 6. Distribution of reviewed literature over the time scale. 


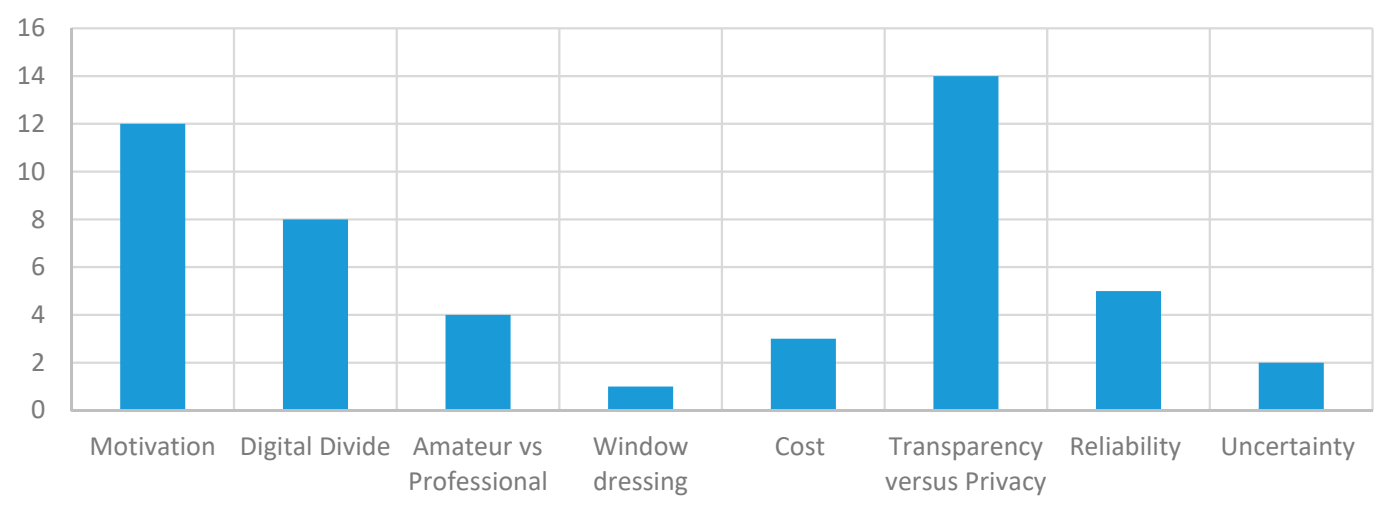

Figure 7. Distribution of existing literature according to attributes.

\section{Attributes of Crowdsourcing}

To fully understand the intricacies involved in any participatory planning and development initiative, it is important to gain perspective into these cyber-physical systems with human-in-the-loop. Brandsen and Holzer [42] mention economics, service management and consumer psychology as the theoretical strands contributing to user and community co-production. The following discussion classifies all attributes of a crowdsourcing procedure falling into the above categories into (1) Human, (2) Data and (3) System characteristics. These characteristics have also been enlisted in Figure 8. Human characteristics refer to the feelings and behavioral patterns of people involved in the process. Data characteristics involve privacy and reliability issues of data. System characteristics hint at the technical details of the project provided by the client and how it can impact the efficient functioning of the system as a whole. The interconnection of these attributes of crowdsourcing makes prediction of its success a very complex task.

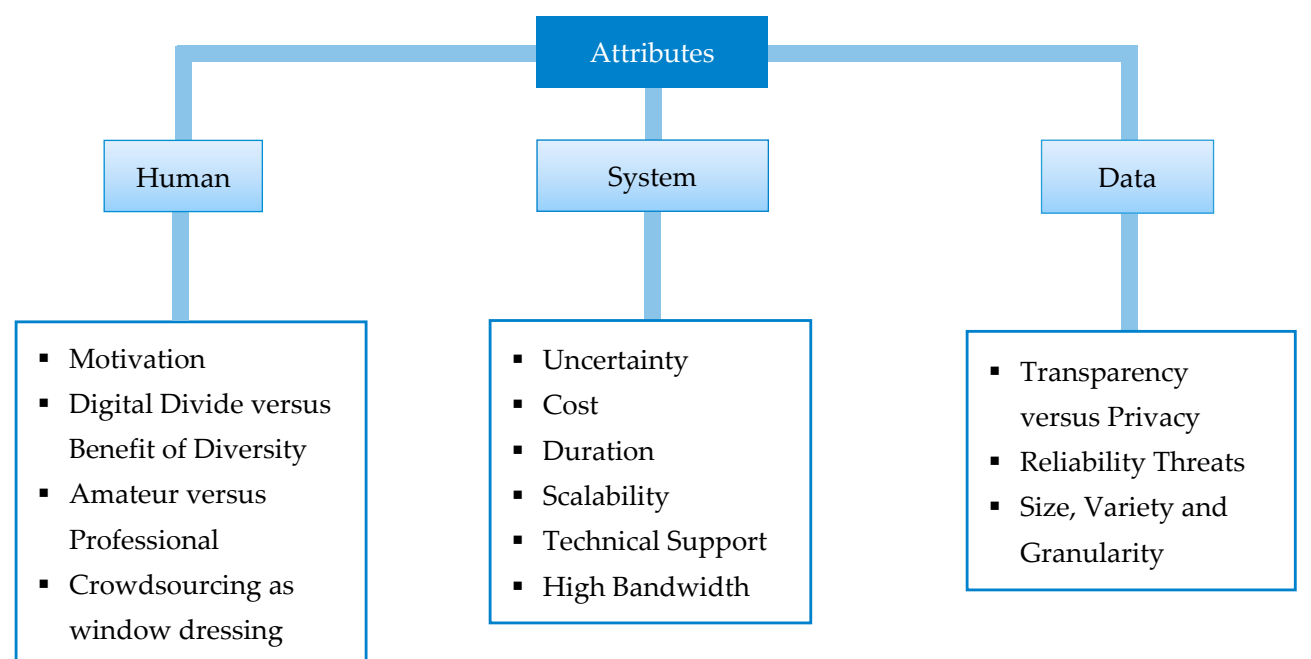

Figure 8. Classification of major attributes: Human, System and Data Characteristics.

\subsection{Human Characteristics}

Human beings form a large portion of the functioning of crowdsourcing platform-be it the clients, the users or the crowdsourcers. It is extremely difficult to predict their individual behavior. However, attempts have been made to study the patterns in their collective behavior, segregating those that are favorable from those that are detrimental to the benefits that the crowdsourcing platforms can bring to the society. This section explores the situations where humans are involved and how those circumstances affect their alacrity towards data generation and submission. These human characteristics have been further divided into four headings: (1) Motivation; (2) Digital Divide; 
(3) Amateur versus Professional and (4) Crowdsourcing as window dressing. Table 2 summarizes the basic human characteristics that affect crowdsourcing.

Table 2. Human characteristics affecting the feasibility of crowdsourcing.

\begin{tabular}{|c|c|c|}
\hline Human Characteristic & \multicolumn{2}{|c|}{ Implications in Crowdsourcing } \\
\hline Motivation & $\begin{array}{c}\text { Conducers } \\
\text { Monetary Incentive } \\
\text { Making a contribution } \\
\text { Utilizing leisure time } \\
\text { Learn new skills } \\
\text { Career advancement }\end{array}$ & $\begin{array}{c}\text { Deterrents } \\
\text { Privacy Issues } \\
\text { High Eligibility Criteria } \\
\text { Absence of good quality internet } \\
\text { Inconvenient design of platform } \\
\text { Ambiguous problem definition }\end{array}$ \\
\hline \multirow[b]{2}{*}{ Digital Divide } & Disparity based on & $\begin{array}{c}\text { Socioeconomic status } \\
\text { Developing and developed nations } \\
\text { Age, gender and disability }\end{array}$ \\
\hline & Other Issues & $\begin{array}{l}\text { Access to internet connection } \\
\text { Quality of connection } \\
\text { Processing ability of computers } \\
\text { Technical Assistance } \\
\text { Affordable Cost }\end{array}$ \\
\hline Amateur versus Professionals & $\begin{array}{c}\text { Amateur Crowd } \\
\text { Unnecessary data generation } \\
\text { Added cost and time } \\
\text { Reliability Threats } \\
\text { No formal training } \\
\text { Transfer of blame to the crowd }\end{array}$ & $\begin{array}{c}\text { Professional Crowd } \\
\text { Threat to professional expertise } \\
\text { Exhaustion of creativity } \\
\text { Low payment to professionals } \\
\text { No minimum wage } \\
\text { No long term agreements }\end{array}$ \\
\hline $\begin{array}{l}\text { Crowdsourcing as } \\
\text { Window-dressing }\end{array}$ & \multicolumn{2}{|c|}{$\begin{array}{l}\text { Inclusion of people for gaining trust in exchange for money or favor } \\
\text { Inputs are taken from the public but never implemented } \\
\text { Decisions taken are mostly influenced by the majority representatives }\end{array}$} \\
\hline
\end{tabular}

\subsubsection{Motivation}

The first step to public participation for urban infrastructure planning is motivating the citizens for making contributions to the project. Identifying and utilizing the right kind of motivation is important for a successful participation scheme for public. The target is not just initiate the participatory action of people but also keep people motivated to engage themselves with the participatory applications in the long run. The key question that this section of the paper strives to answer is that what is it that makes people want to engage themselves in the information collection and planning process of a smart city. It is important to study the motivators of crowdsourcing platforms. This is because by manipulating the factors of motivation, the application can be made more attractive for the users to fully engage themselves in the system.

Deci and Ryan [43] categorized motivations as extrinsic motivation and intrinsic motivation. Extrinsic motivation means that the behavior of the person is driven by conditions outside of an individual in contrast to intrinsic motivation, which comes from within. In an attempt to prove that recognition by peers and opportunity to learn new skills to be the topmost motivators, Brabham [44] concluded that opportunity to make money was the most important motivator for participation in crowdsourcing platforms. Monetary benefits are clearly extrinsic motivators. The issue with this motivation is that clients usually opt for crowdsourcing in order to optimize their cost of the project. Thus, paying people for their work is less preferable for the service provider and cannot be employed everywhere. Also, since there is a huge number of people involved, the payment each one of them would get would be quite small which makes monetary incentive not such a great motivator till the payment amount is substantial. There are issues with valuating the work with money. A non-paid worker may put in more effort for the cause in comparison to a paid worker who knows that no matter how much effort he puts in, his work will earn a lower amount. Also, money can give connotations of buying the crowd for personal gains and reduce the initiative to a biased endeavor. 
Working to contribute for the betterment of the society is a motivator in the category of intrinsic motivation. There is also an incentive for human interaction, even with strangers. Working together towards a common goal of improving infrastructure creates a strong bond of harmony among citizens. Another intrinsic motivation could be for fun and to get rid of boredom $[45,46]$. People who are full time workers at a job may want to take out some time and take part in an activity just for fun, or to freshen themselves up. Sometimes people take enough time to do the jobs assigned to them as one takes out time for their hobby for any other part time job. Many see this as an opportunity to pursue their interest and build new skills. A still many participants see this as a recommendation for an advancement in career [46]. Simplicity of tasks also serve as a motivation for public participation in contrast to difficult tasks $[47,48]$.

We have talked about what motivates someone to take part in data collection and planning process. There is indeed a need to talk about what discourages people from participating in these online applications. First and most important is protection of privacy. No one will want to associate themselves with an initiative in which user information is leaked, knowingly or unknowingly, to government agencies, hackers or any other malicious groups who can use it with an intent of harm. We will discuss privacy issues in more details in the further sections.

Other deterrents of motivation for participation include eligibility criterion. Many people think that they do not qualify to do a job and hence, will not even sign up into the platform. This may have issue with limiting diversity of the crowd and make the decision-making process a bit biased. A user-friendly platform with easy-to-learn-and-use features add to the motivation of people to use the application in their daily life. The incentive for working is also more if the problem statement and goals on the work are clearly defined. It goes without saying that a good internet connectivity forms the basis of these crowdsourcing applications for public planning process and thus, its presence or absence is the biggest deciding factor for the success of a planning process through citizen involvement.

\subsubsection{Digital Divide}

The vision of smart cities involves a significant influence of people's engagement in the planning, development and running of infrastructure systems. On one hand, the leaders want to follow an inclusive approach to people's participation involving people from diverse groups and on the other hand, more than half of the people around the world still do not have access to the internet. There exists a substantial level of disparity in the socioeconomic status of the people from all around the world. There is also a considerable technological gap between the developing and developed nations on an international scale. Digital Divide is not just limited to access to the internet services but also in the unequal access to new communication technologies [49]. This envelops the subject of quality of connection, processing ability of computers and difficulty in obtaining technical assistance. The issue is just not the presence of internet services in smart cities but their availability at an affordable cost and in good quality.

Another field of concern is the demographics of the population involved. Most of the technology and latest infrastructure solutions do not consider this aspect of the society. The inclusive approach should also keep in mind that it is not just the minor sections of the society that we need to include in our solutions but also the technology should be easy to use for the all the end-users including aged population and the persons with disabilities.

Elimination of digital divide will not occur with providing access to technology and internet services. The uneducated youth will be needed to be given digital education and training so that they can contribute to a large section of the smart communities.

\subsubsection{Amateur versus Professionals}

It is always a great challenge to identify whether the problem should be outsourced for public participation or it should be left to be dealt with by professionals alone. Also, another key question is whether the 'supposed' amateur crowd can work together and give superior service deliveries and 
better quality outcomes than professionals in that field. Taking a look at this issue from one perspective, studies suggest that non-professional participants may sometimes not have the qualifications to understand the problem and more so, to propose solutions and hence may lead to generation of huge amount of unnecessary data, which might become difficult to deal with. Their solutions need to be edited and refined before they are released to be used. This can lead to substantial amount of added costs of time as well as money to the client. This is true when a certain level of technical knowledge is required in order to participate in the project planning. There are also issues related to the reliability of data provided by the crowd while crowdsourcing data from amateurs. Many a times a hidden user identity makes it difficult to know the real intentions of a person participating in such planning platforms. The key focus of this perspective is to include users for their need and let the professionals come up with an innovative idea to help the users [50].

Some studies point out that it may actually not be healthy to exploit the creativity of the professionals associated with the organization indefinitely. Over-utilization of company-internal knowledge may exhaust them of their innovative schemes. After a certain period of time, hiring more professionals for the job would not lead to an expected increase in output [51]. In an experimental study comparing idea generation by users and professionals, Poetz and Schreier [52] found that the best overall ideas are mostly concentrated among users than with a firm's professionals. They suggest that the combination of inputs from both amateurs and professionals is an optimal way of idea generation. Crowdsourcing can thus be seen as a threat to professional expertise [53]. Brabham suggests that crowdsourcing should actually be seen as a supplement to professional contribution and not as a replacement.

Another key perspective under this discussion is the underlying presumption that non-professionals form the majority of the crowdsourcers, thus terming them as amateurs. Amateurism in itself has a very vague definition. It may mean someone who seeks no job and performs an activity for non-profit dividends or someone who may not possess knowledge or have formal training in a specific field. Also, experience in the crowdsourcing platform promotes one from the amateur level to a professional level. A new user may not be able to produce results as good as someone who has been in the field since a long time. Brabham [54] states that the labelling of the crowd to be low-cost non-professionals and good for business, puts the people in a wrong stance. Their hard work and creative labor is unfairly exploited and unjustifiably lowly paid. They incur costs of using electronic devices and internet connection but such costs are never addressed by the client. There are no unions, no long term agreements, no minimum wages and hence, the clients are not obliged to pay the people and can dismiss them anytime. It becomes easier for the clients to gain publicity if their endeavor becomes a success. But crowdsourcing also opens gates for transferring blame of failure to the crowd and justifying hiring of professionals than involving the crowd.

It is imperative to address the nuances in this attribute for striking a proper balance between what people want and what the government agencies or private parties of smart cities are trying to achieve through involvement of people.

\subsubsection{Crowdsourcing as Window Dressing}

It is not wise to be under the assumption that inclusion of people's opinions in planning is same as their incorporation in implementation of ideas. Politicians may use this as a tool to gain trust of citizens and come to and stay in power [55]. Unless there is a certain level of transparency in the working of the technical platform, there is no way the citizens can know how a system is operating to process the decision voted by the crowd. Citizens' votes can also be influenced in exchange for favor or money and the whole process of involving the people would just be a pretense.

The diversity of the crowd involved also gives us another perspective to look at this issue. No matter how many attempts are made, a single decision can never satisfy the wishes of all the citizens. The operating principle gets reduced to a decision taken in the interests of the majority but not hurting the interests of the under-represented groups. Also, sometimes the majority may take a 
decision that may be immoral and inhuman to implement [56]. Trottier [57] suggests that the crowd is very susceptible to give in to racial biases and thus, it is not safe to leave the decision making procedure limited to public voting. If the government ignores such sentiments of the crowd, it can be deemed as non-functioning, biased, arrogant and may totally lose the support of the masses. Such a thing is not at all desirable if peace and safety need to be established keeping in view the visions of a smart city.

\subsection{Data Characteristics}

With the advent of the internet based applications being deeply integrated into the lives of common people, there is a huge amount of data being generated. This can help the clients to use the information contained in this data to the benefits of the society, making their lives more comfortable. However, if such an information falls into the hands of an organization with malicious intentions, the outcome would be harmful for the society. This section, thus, deals with the necessity of transparency in the data collection, processing and implementation procedures while taking a peek into the privacy threats associated with such an act. Also, the reliability of data recorded is explored in this section. Other aspects of data such as the magnitude and speed with which it is produced, the types of data which are available and the scale at which it is recorded and how that poses a challenge to the clients in providing rapid solutions to citizens' concerns is also inspected. This discussion takes place under three headings: (1) Transparency versus Privacy; (2) Reliability threats and (3) Size, Variety and Granularity of data. Table 3 encapsulates the major data characteristics that affect crowdsourcing.

Table 3. Data characteristics affecting the feasibility of crowdsourcing.

\begin{tabular}{|c|c|c|}
\hline Data Characteristic & \multicolumn{2}{|c|}{ Implications in Crowdsourcing } \\
\hline Transparency versus Privacy & $\begin{array}{c}\text { Transparency Effects } \\
\text { Keeps a check on agency functioning } \\
\text { People are not misled by the media } \\
\text { Feeling of responsibility among crowd } \\
\text { Promotion of inter-cultural hatred } \\
\text { Promotes reliability of data }\end{array}$ & $\begin{array}{c}\text { Privacy Threats } \\
\text { Easier to track daily routine } \\
\text { Hacking attacks on personal data } \\
\text { Fake user identity for malevolence } \\
\text { Unsafe to report delicate information } \\
\text { Lack of security awareness }\end{array}$ \\
\hline Reliability & $\begin{array}{l}\text { Non-intentional Reliability Issues } \\
\text { Lack of awareness among users } \\
\text { Limitations of technology involved }\end{array}$ & $\begin{array}{c}\text { Intentional Reliability Issues } \\
\text { Saving computational cost } \\
\text { Misleading clients to wrong solutions }\end{array}$ \\
\hline Size, Variety and Granularity & \multicolumn{2}{|c|}{$\begin{array}{l}\text { Large data size and velocity of generation increases time and labor costs } \\
\text { Data collected in the form of texts, images and videos needs different handling } \\
\text { Intricate details widen the scope of the project as well as the associated costs }\end{array}$} \\
\hline
\end{tabular}

\subsubsection{Transparency versus Privacy}

The key question we want to address in this section is what happens when such systems fail to preserve privacy of people involved. Another problem arises if the people start using the platform for their own hidden motives. Encroachment on privacy of users is one of the biggest deterrents of participation in crowdsourcing platforms. One of the largest concerns of the online cloud of data is the hackability of such platforms and risk of leakage of private information to people with malicious intentions. Another perspective to look at this problem is that too much confidentiality of information is also detrimental for the inclusive planning to be implemented properly.

Transparency in crowdsourcing and participatory planning platforms is vital for innumerable reasons. Increasing transparency makes interaction with citizens easier and it also convenient to address the problems of specific communities separately if their identities is known. Transparency helps to keep a check on the agencies and ensure their uncorrupted functioning [58]. The people will not be misled by the media but get a sense of the prevailing condition of the problem. It also makes it easier for whistleblowers to come out in the open and release sensitive information to keep people informed. Huang and Fu [59] also put their perspective in favor of increasing social transparency in crowdsourcing platforms. According to them, releasing demographic information makes people perform better than when they work anonymously. They feel a sense of responsibility to their team 
mates if their identity is not anonymous. Also, in a competition-based scheme, participants feel more motivated to outperform their opponents if their identities are revealed. But the behavior of a person to this stimulus depends on his personal interests and thus, this theory of transparency does not seem to be universally applicable. Another thought on this issue is that revelation of personal information may also lead to promotion of hatred in inter-cultural groups and encourage a general racial bias among participants which will not be fruitful if we want to get a collective output from citizens for upliftment of the society as a whole, in concordance with the smart city vision. Also, transparency promotes reliability of data. It is very difficult to eliminate the contribution of robots and other spam workers in absence of user data to preserve worker privacy [60].

Releasing of personal information for increasing transparency in the working of a system is a threat to the security and privacy of users as well the clients. Almost all applications today collect location and time data from users. It is used for carpooling apps, for environment monitoring applications as well as for traffic-related applications. Accurate analysis of such data can highly predict day-to-day routine of users and also their home and place of work [61]. Such information falling into the hands of criminals can be detrimental to the whole idea of a safer city in the smart city vision. Closed-circuit television (CCTV) surveillance freely available to the citizens can trigger criminals to track positions of police and plan their actions [57]. Government can use this personal information to oppress the people in opposition of the ruling party. The lack of transparency in the processing of data collected from users victimizes them at the hands of secret agencies, government, criminals and even terrorist organizations. Most of the sharing of information occurs through lack of security awareness in users [62]. Most of the users do not have the knowledge of what happens with the information provided by them. Access to such knowledge will help them make informed choices of providing user data. Release of any sensitive information like violence or corruption may pose hazard to the user who reports it if his identity is not kept private.

Mobile devices used for crowdsourcing initiatives are also not free from hacking attacks. Traditional cryptographic techniques for privacy cannot be used in handheld devices because of their limited memory and computational capacity [62]. Attackers may get access to name, location and credit card details of users and can steal their user identity for personal gains. All the above privacy breaches of users need to be completely eradicated and such malicious activities need to be continuously monitored.

\subsubsection{Reliability Threats}

The whole smart city initiative relies on obtaining data from the users and its unbiased analysis to provide better infrastructure systems to the citizens. Be it disaster relief measures or crowdsourcing for Wikipedia, one looks for a certain level of reliability in the information provided before it can be presented and acted upon for use. Taking actions on information that is uncertain may lead to wastage of money, time and human labor. Thus, optimization of the three resources of crowdsourcing- money, time and labor- is greatly influenced by the level of reliability of data involved.

Reliability of data refers to the degree of accuracy present in the data provided by the users. Reliability issues can be divided into two categories: (1) non-intentional and (2) intentional.

\section{Non-intentional Reliability Issues:}

Non-intentional reliability issues can be born due to the lack of awareness among users or limitations of the technology involved. In location-based data, for example, the GPS technology needs to be highly accurate for the system to be reliable [63]. Street Bump, a road hazard-detection app, launched by New Urban Mechanics in July 2012, could not differentiate between pothole and other bumps on the road [64]. This shows the limitation of using technology in producing reliable information. If people should have faith in the data provided by the application, it should be correct. They will not use the application once the trust is lost. Sometimes, there might be a bug in the 
application that could produce wrong information. The users can also upload wrong information sometimes due to carelessness, misunderstanding, personal bias or lack of experience [61].

Intentional Reliability Issues:

Willful reporting of incorrect and invalid data by the users can be termed as an intentional breach of reliability in crowdsourcing. Dishonest workers may provide wrong computing information to save computational cost. In a paid crowdsourcing platform, the main aim of participants eventually is to earn money. This can cause them to provide more and more irrelevant data in order to gain monetary benefits. These applications may also become a source for misleading authorities in times of emergencies. In case of a terror attack, the attackers themselves can report false injuries and damage to redirect emergency responses to the wrong locations. Also, it is difficult to know who the user of the mobile phone is when data is getting recorded.

The greatest challenge of all is to categorize whether problems in data are due to erroneous working of gadgets and people or due to malicious intentions of users. Thus, it becomes crucial to check the reliability of data before releasing it to the public for use. Techniques for testing the reliability of data will be discussed in the further sections.

\subsubsection{Size, Variety and Granularity of Data}

The amount of data generated in crowdsourcing is huge. The collected data can be in the form of contributions of citizens, metadata and data on participants' activities [65]. On one hand, this data gives us a diverse taste of opinions of people but on the other hand, the huge size of data also makes it difficult to handle privacy and reliability issues [66]. Big size of data also implies time and labor costs in processing the information. The challenge is not only to deal with the huge amount of data but the velocity at which it is being generated in real time. Some application developed for disaster mitigation may usually not see much site traffic but as soon as a disaster hits, the velocity of data may increase manifolds and can become a huge challenge to handle. One such instance happened when a 7.0 magnitude earthquake hit Haiti in 2010 [30]. The Ushahidi platform had not seen so many number of requests before and it became impossible for the relief force to read all the reports that were getting uploaded on the platform for help.

No restraint is usually put on the format in which idea needs to be submitted in order to maximize the creative capacity of participant. Thus, the data being generated from crowdsourcing can be in the form of text, pictures or videos. The systematic analysis of each of the above variety of data requires different levels of technological expertise. The information present in the form of text may need to be filtered out using tools of big data analytics. Passive data analysis involves scanning and filtering data from social networking sites or recording surfing habits of users. This type of data analysis needs an advanced level code to identify and predict relevant patterns in the information. Advanced image processing techniques need to be used for filtering data in images and videos. Employing people's involvement for scanning of information in images and videos can be time-taking and costly. But one can argue that recognition of actions and emotions involved in the picture is better done by humans than by artificial intelligence. As discussed in the paper, people can sometimes act in a very biased manner against people from certain races but such a behavior is easier to predict than if the bias is embedded into the algorithm developed by a biased person.

The next attribute of data is its granularity. It is a good question to ask that how detailed should the data be so that our final goals are achieved. It is satisfactory to believe that the more detailed the information is, the better results it is going to lead to. But details add on to the storage cloud of the data and optimization of cost and service delivery will happen if the size of data is just okay to give satisfactory results. Intricate details in data broaden the scope of work and push the limits of the project and hence, is more desirable. Lower granularity of data makes it easier for us to segregate and store information and refines search options for the particular data. Clickstream data is the data generated when one surfs through the websites. It tracks every move of the cursor and every new page one 
opens. But a huge portion of this data is worthless to produce any patterns or lead to any conclusions on human interactions with the web [67]. Inmon argues that data should not be stored at the lowest level of granularity but rather at the lowest level of usefulness. This is well in synchronization with the optimization vision of smart city planning

\subsection{System Characteristics}

This section explores the features of the project for which the platform is built and how it affects crowdsourcing which is to be employed as a tool for data collection. The cost borne by the client as well as by the participants is looked upon. The duration for which the project is undertaken and the scale which the project encompasses is also talked about. Another discussion in this section is based on the technical support that should be provided to both the client as well as the participants. Lastly, the main concern of every client, that is, the uncertainty in production of results, in terms of feasibility of the project, is also investigated. Thus, the discussion in this section is divided into five major categories: (1) Cost; (2) Duration; (3) Scalability; (4) Technical Support and (5) Uncertainty Issues.

\subsubsection{Cost}

We look at the cost analysis of crowdsourcing from two perspectives: (1) cost to the client and (2) cost to the participants. Crowdsourcing is deemed to be a cheaper way of collection of data and decision-making than by hiring a team of professionals to do the same job. The initial costs of establishment of the platform, manufacture of sensor devices and cost involved in advertisement is all that is required. Helmchen and Penin [68] talk about differences in cost of crowdsourcing routine activities and crowdsourcing content. Crowdsourcing routine activities is easy but time consuming. Thus, it is better to use citizen's participation for such activities than by hiring professionals to do the job. The rewards given to citizens in exchange for their work are also modest and hence, do not cost much to the government or the client. In crowdsourcing content, people invest not only their time but also bring ideas with them. Most of the such crowdsourcing processes tend to be lowly rewarding as people are usually willing to work because of their intrinsic motivation.

From the perspective of participants, if the data is automatically and simultaneously getting collected along with their other work, they are not accounted for much extra costs even in terms of time and money. The cost of their electronic gadgets, internet connection and labor they provide is the only cost incurred [63].

\subsubsection{Duration}

The smart city vision aims to engage citizens in projects that get embedded in day-to-day lives of people for a long time after they are introduced. A larger duration project attracts more participants [48]. They have more time to propose solutions and bring improvements in the existing system. Longer duration projects also create a sense of long-term engagement with the community among its citizens. Long duration projects require less intense efforts from the citizens and hence, they can contribute to the society in their own way and on their own pace.

\subsubsection{Scalability}

The scale of the platform refers to the region the project encompasses. The smart city projects can be a small portion of a worldwide initiative in a particular field. A large-scale project ensures more diverse ideas for the betterment of citizens. No one is left behind in the process of progress. Also, costs of setting up a small portion of an already established worldwide system would be much lower than starting the project from scratch in every city. In this way, people can learn from the mistakes in the platform from all around the world and improvise on them. 
public sector. The government can seek public-private partnerships or crowdfunding processes in order to raise money for the process of development of internet services in the city. Providing digital access to people will raise their motivation in public participation applications, increase diversity of ideas and give a boost to amateurism. As more and more people can be reached out to, the chances of misuse of data by political faces will be much lower. Inclusion of a wide variety of people will raise concerns about privacy of data because of the increase in transparency of information available. The action will have an ambiguous effect on the reliability of data. It can increase with more participation from people or decrease at first as people learn to use the technology and increase eventually in the long run, when all people are digitally literate. The size of the data will no doubt increase and make it more difficult to handle. The cost will be high for the establishment of new services. Uncertainty will decrease as we will have more people working for the same final goal.

\subsection{Training and Feedback}

All the participatory platforms can include an introductory video with a set of instructions to use the platform. It may also redirect the users to certain online lectures that inculcate the skill required to solve the problems posted on the platform. This would be of great help to the senior citizens, uneducated youth and other unprivileged sections of the society. It will also help to provide a basic training to the group of amateur crowdsourcers leading to better quality outputs. Instructions can also be given for privacy awareness about Do's and Don'ts and general privacy attacks. A vast majority of participants wish to gain feedback on the quality of work they are doing [47]. This helps them to know if they are lacking somewhere and motivates them to perform better. Therefore, training and regular feedback is bound to increase people's participation.

\subsection{Incentives}

The biggest motivation for people participating for smart city infrastructure development should be that they are the users of those services and their contribution to the cause is going to benefit them sooner or later, if not immediately. The infrastructure systems themselves can serve as incentives for people. Participation of people can be initiated by luring them through free car parking, travel allowances, discount coupons for shopping and so forth. Monetary incentives have been shown to be the best motivator for crowdsourcing. Giving out money to people for their contributions is sure to motivate them to work for a cause. But such an incentive is very short lived and as soon as you stop payments the people would stop contributing. Governments for city planning initiatives want to optimize their financial expenditures and should consider this as the last resort if nothing else is motivating enough. Monetary benefits could cost too much to the government for building a smart city. It may also lead to people getting involved in unfair practices to earn money through this which in turn, can decrease the reliability of results. Another perspective to look at this is that monetary awards can also ensure the quality of results if the reward amount is high. Thus, the straight relation between money and reliability is also ambiguous.

\subsection{Easy Application Procedure}

In a smart city project, the goal must be to include as many people in the planning process as possible. Easy application procedure means that there is not much information required before one signs up on the platform and starts his work. This is likely to ensure a large scale public participation for the greater good. Crowdsourcing of data may not require any qualified crowd for information collection while some qualifications may be necessary if a decision process regarding a particular topic needs to be taken in order to avoid inputs of the gullible crowd. Lower barriers to entry is also detrimental for privacy of users as they can fall victim to a cyber-attack from another anonymous user and there would be no way to track him down. A way could be to keep low barriers at first but then after a few days make it compulsory to provide more information else the account would get frozen. 


\subsection{Clear Problem Definition}

There should be no confusion among citizens regarding what their work is going to be when they are participating. The work can be categorized as submitting ideas, uploading data, validating uploaded information, making monetary contributions and so forth. A clear demarcation must exist between what things are to be handled by citizens and at what point in time and space should officials enter the picture and where joint contribution of citizens and officials is required. Any matter relating to federal laws, reports of abuse, or security concerns must be reported to the authority directly. While some sensitive issues need to be released to both people and the authorities so that proper transparency is maintained in the action required to mitigate those problems.

\subsection{Recognize the Contribution of an Individual}

Thanking a community for its participation is easy but to point out individuals for their collaborative effort is very challenging. People wish to gain recognition for their contribution [47]. For example, doctors working in an online-based medical service application may be given certificate of recognition. An organization that was quick in emergency response and providing help in times of disaster through a surveillance map creation software may be given recognition for their generous deeds. Giving out certificate of participation or progress for their exceptional contribution can also help one to advance one's career as mentioned in one of the motivations in crowdsourcing. Another beneficial aspect of this to both the participant and the client can be recruitment for permanent jobs through crowdsourcing. The people who are consistently producing remarkable results can be given full-time employment in the same project. The risk associated with delivery of performance of the employ would be significantly less through this method.

\subsection{Validating the Data}

This discussion can be approached in two ways-validation of information collected through crowdsourcing and ranking of ideas for decision-making. It is imperative to cross check the data for its reliability before it can be released on the platform to the users. Weaver et al. [69] mentions three ways of ensuring trust in a platform: by Group Membership, by Crowdsourcing and by Machine Learning. A reliability score can be associated with a particular user or a member of the group and that score can be increased based on the contributions made by the user. A user can link himself with a particular group based on their field of work or their place of residence. The user can then request high reliability level through the group. He can also be a part of several groups without sacrificing his reliability level. Information provided by a highly reliable user should be given preference. The another most common way of conducting reliability checks could be through crowdsourcing by engaging citizens for flagging the information as true or not. This can be done in two ways, by a thumbs up/down option or by using a rating scale. Despite the popular use of the above methods for information validation, Riedl et al. [70] state that these methods do not produce valid outputs. They mention that granularity of scale positively influences its rating accuracy as well as users' satisfaction with their ratings. It is true because one cannot express his true opinion as a strict yes or no. The two-way rating scale can produce biased results as it compels one to take a side and thus, more neutral opinions are completely wiped out. The last recommendation involves the use of machine learning in validating information. The information about weather, natural disaster, traffic, pollution and so forth, can be validated easily and instantly using GPS sensors and other measuring devices. Riedl et al. [70] suggest the use of a multi-attribute scale in which users could rate the ideas based on attributes like originality, usability, feasibility, cost and so forth. Inclusion of experts for the final decision is also desired to ensure reliability. Hirth et al. [71] bring two approaches for validating information. In the Majority Decision (MG) Approach, if the same information is uploaded by a vast majority then it is deemed as true. In the Control Group (CG) Approach, the information is sent to another set of people for 
validation. A more reliable but time taking way would be to send filtered opinion of the crowd to the experts for a final review before release.

Validation of data is a time consuming process and hence, there may be a substantial delay in receiving and outsourcing information. The process of validation through crowdsourcing may hurt ego of many users. They may feel that their contribution needs an approval of fellow workers before being released and hence, may be demotivated to work for the platform.

\subsection{Privacy Protection}

The primary initiative in providing privacy protection would be by educating the crowd about various types of privacy attacks so that they can make an informed choice of what to and what not to share. A feature can be included in the platform that asks the user about the granularity of their information that they want to share. Wang et al. [62] mention a few dimensions of privacy preferences for the level up to which the user wants to share the information under that dimension. The dimensions include time (time of the day, day of the week), location (street, area, city, state, country), visibility of data (close friends, everyone on the application, everyone on the internet), time of sharing (during the work, after the work, not at night) and expiration of sharing. Prabaker et al. [72] mentions that these privacy preferences are highly dependent on the contextual attributes and may change from time to time. Also, most of the users are not good at choosing what is the best privacy setting for them. The users hardly change their settings after getting logged in while most of them work on default privacy settings.

There are certain inbuilt features available in the mobile devices to secure user from any web attack. Features like secure Wi-Fi automatically blocks pop up notifications, untrusted sites, malicious downloads, advertisements and so forth. Some existing networking platforms like WhatsApp uses end-to-end encryption on both text messages and calls. Such an encryption can be applied to the data collected through crowdsourcing for developing infrastructure systems. It would ensure that data is not leaked in transmission and only users can have access to it. Halder [73] talks about development of a crowdsourcing index (CI) for various smart city applications. This index shall be mathematically derived depending on a Digital Safety Index (DSI) and a Privacy, Security and Data Protection (PSDP) Level. This can be helpful on assessing the application based on its effectiveness in privacy protection.

\section{Concluding Remarks}

Through the discussions above, this study takes a peek at the enormous deficiencies that the existing platforms, employing the use of crowdsourcing for data collection, analysis and finding solutions, suffer from. Therefore, it is observed that there is a pressing need to cater to the shortcomings as discussed in the paper. An attempt to summarize the existing practices of crowdsourcing and the attributes that govern the feasibility of crowdsourcing have been thoroughly discussed. The human characteristics include reasons for motivation of participants, lack of digital equality in different sections of the society, issues related to the treatment of crowdsourcers as amateurs or as professionals and how crowdsourcing may be used as a veil to fulfil one's own hidden motives. The discussion under data characteristics covered the need for transparency, threats to privacy of participants, issues related to the reliability of data and the size, variety and granularity of data being generated. The system characteristics refer to the aspects regarding the project for which crowdsourcing is employed, such as its cost, duration, scalability, technical support and certain uncertainty issues. It is, however, interesting to note the interdependencies that exists among the cross-domain attributes, make the prediction of the feasibility of crowdsourcing as a tool highly challenging.

Some recommendations for incorporation in the future urban infrastructure systems have also been discussed, with examples. These include providing digital access to all the sections of the society, giving required training to the participants and feedbacks to their performance, providing incentives to them, keeping a lower eligibility criterion for participation, stating a clear problem definition, validation of data being uploaded on the platform and methods to protect the privacy of participants. 
The findings presented in this study shall assist the private clients as well as the government agencies to build a robust system for providing services to the citizens that employ their participation in obtaining solutions or in decision making. This study shall also aid the users to know the risks they are exposed to while entering their information on these platforms and encourage them to make an informed choice before they use such platforms. Also, it shall help the crowdsourcers to demand the right kind of compensation according to the level of output their contribution is generating, which shall prevent the exploitation of their creativity. Thus, it is hoped that through a collective knowledge of the dynamics involved in the process of crowdsourcing, both the users and the developers would be able to reap its full benefits and live in a safer and smarter urban infrastructure systems that promote resilience to evolving stressors [74,75].

Author Contributions: Conceptualization, P.S. and A.M.; methodology, P.S.; formal analysis, P.S.; investigation, P.S.; resources, P.S.; data curation, P.S.; writing — original draft preparation, P.S.; writing — review and editing, P.S and A.M.; visualization, P.S.; supervision, A.M.

Funding: This research received no external funding.

Acknowledgments: The authors would like to thank the TAMU-IITK Summer Exchange Programme 2017 for supporting the undergraduate research internship of the first author. Any opinions, findings and conclusions or recommendations expressed in this material are those of the author(s) and do not necessarily reflect the views of the TAMU-IITK Summer Exchange Programme.

Conflicts of Interest: The authors declare no conflict of interest. The funders had no role in the design of the study; in the collection, analyses, or interpretation of data; in the writing of the manuscript and in the decision to publish the results.

\section{References}

1. Cohen, B. Urbanization in developing countries: Current trends, future projections, and key challenges for sustainability. Technol. Soc. 2006, 28, 63-80. [CrossRef]

2. Albino, V.; Berardi, U.; Dangelico, R.M. Smart cities: Definitions, dimensions, performance and initiatives. J. Urban Technol. 2015, 22, 3-21. [CrossRef]

3. San, J. CA-Official Website-Smart City Vision. Available online: https://www.sanjoseca.gov/index.aspx? nid $=5289$ (accessed on 20 July 2017).

4. Nam, T.; Pardo, T.A. Conceptualizing Smart City with Dimensions of Technology, People, and Institutions. In Proceedings of the 12th Annual International Digital Government Research Conference: Digital Government Innovation in Challenging Times, College Park, MD, USA, 12-15 June 2011; pp. 282-291.

5. What Challenges Do Smart City Leaders Struggle With?-Smart City Hub. Available online: http:/ / smartcityhub.com/governance-economy/challenges-smart-city-leaders/ (accessed on 28 June 2017).

6. Angelidou, M. Smart city policies: A spatial approach. Cities 2014, 41, S3-S11. [CrossRef]

7. Al-Hader, M.; Rodzi, A.; Sharif, A.R.; Ahmad, N. Smart city components architecture. In Proceedings of the 1st International Conference on Computational Intelligence, Modelling and Simulation (CSSIM 2009), Brno, Czech Republic, 7-9 September 2009; pp. 93-97.

8. Anthopoulos, L.; Panos, F. From Online to Ubiquitous Cities: The Technical Transformation of Virtual Communities. In Proceedings of the International Conference on e-Democracy, Vienna, Austria, 7-8 September 2009.

9. Simonofski, A.; Asensio, E.S.; de Smedt, J.; Snoeck, M. Citizen participation in smart cities: Evaluation framework proposal. In Proceedings of the 2017 IEEE 19th Conference on Business Informatics (CBI 2017), Thessaloniki, Greece, 24-26 July 2017; pp. 227-236.

10. Coe, A.; Paquet, G.; Roy, J. E-Governance and Smart Communities. Soc. Sci. Comput. Rev. 2001, 19, 80-93. [CrossRef]

11. Caragliu, A.; Del Bo, C.; Nijkamp, P. Smart cities in Europe. In Proceedings of the 3rd Central European Conference in Regional Science, Košice, Slovakia, 7-9 October 2009.

12. Howe, J. The Rise of Crowdsourcing. Wired Mag. 2006, 14, 1-5.

13. Prpic, J. Next Generation Crowdsourcing for Collective Intelligence. arXiv 2017, arXiv:1702.03109.

14. Goodchild, M.F. Citizens as sensors: The world of volunteered geography. GeoJournal 2007, 69, 211-221. [CrossRef] 
15. IBM. A Vision for Smarter Cities: How Cities Can Lead the Way into a Prosperous and Sustainable Future; IBM Global Business Services: Armonk, NY, USA, 2009.

16. Eger, J.M. Cities: Smart growth and the urban future. The San Diego Union Tribune, 13 Feburary 2000.

17. Eger, J.M. Smart growth, smart cities, and the crisis at the pump a worldwide phenomenon. I-Ways 2009, 32, $47-53$.

18. Ertiö, T. M-participation: The emergence of participatory planning applications. In Research Briefings; Turku Urban Research Programme's Publication: Turku, Finland, 2013.

19. Brabham, D.C. Crowdsourcing the Public Participation Process for Planning Projects. Plan. Theory 2009, 8, 242-262. [CrossRef]

20. Bonabeau, E. Decisions 2.0: The Power of Collective Intelligence. MIT Sloan Manag. Rev. 2009, 50, 45-52.

21. Bugs, G.; Granell, C.; Fonts, O.; Huerta, J.; Painho, M. An assessment of Public Participation GIS and Web 2.0 technologies in urban planning practice in Canela, Brazil. Cities 2010, 27, 172-181. [CrossRef]

22. Anttiroiko, A.V. City-as-a-platform: The rise of participatory innovation platforms in finnish cities. Sustainability 2016, 8, 922. [CrossRef]

23. Komninos, N. The Age of Intelligent Cities: Smart Environments and Innovation-For-All Strategies; Routledge: Abingdon, UK, 2014.

24. Encalada, L.; Boavida-Portugal, I.; Ferreira, C.C.; Rocha, J. Identifying tourist places of interest based on digital imprints: Towards a sustainable smart City. Sustainability 2017, 9, 2317. [CrossRef]

25. Tenney, M.; Sieber, R. Data-Driven Participation: Algorithms, Cities, Citizens, and Corporate Control. Urban. Plan. 2016, 1, 101. [CrossRef]

26. Winter, J. Algorithmic Discrimination: Big Data Analytics and the Future of the Internet; Springer: Cham, Switzerland, 2015; pp. 125-140.

27. Arroub, A.; Zahi, B.; Sabir, E.; Sadik, M. A literature review on Smart Cities: Paradigms, opportunities and open problems. In Proceedings of the 2016 International Conference on Wireless Networks and Mobile Communications, WINCOM 2016 Green Communications Networks, Fez, Morocco, 26-29 October 2016; pp. 180-186.

28. Degbelo, A.; Granell, C.; Trilles, S.; Bhattacharya, D.; Casteleyn, S.; Kray, C. Opening up Smart Cities: Citizen-Centric Challenges and Opportunities from GIScience. ISPRS Int. J. Geo-Inf. 2016, 5, 16. [CrossRef]

29. Smartbin I Smart City I Smart Monitoring I Ultrasonic Level Sensor. Available online: https: / /www.smartbin. $\mathrm{com} /$ (accessed on 22 July 2017).

30. Heinzelman, J.; Waters, C. Crowdsourcing Crisis Information in Disaster-Affected Haiti. Phys. Rev. Lett. 2010, 96, 258102.

31. OpenStreetMap. Available online: https:/ / www.openstreetmap.org/\#map=15/29.4390/-98.4965 (accessed on 23 July 2017).

32. Person Finder. Available online: https://google.org/personfinder/2018-kerala-flooding (accessed on 18 August 2018).

33. Gao, H.; Barbier, G.; Goolsby, R. Harnessing the crowdsourcing power of social media for disaster relief. IEEE Intell. Syst. 2011, 26, 10-14. [CrossRef]

34. Smart Solar Charging Station Strawberry Tree I Strawberry Energy. Available online: http:/ /senergy.rs / proizvodi/strawberry-drvo/?lang=en (accessed on 22 July 2017).

35. Soofa Bench-Soofa. Available online: http://www.soofa.co/getsoofa (accessed on 22 July 2017).

36. Google Flu Trends. Available online: https://www.google.org/flutrends/about/ (accessed on 21 July 2017).

37. Dugas, A.F.; Jalalpour, M.; Gel, Y.; Levin, S.; Torcaso, F.; Igusa, T.; Rothman, R.E. Influenza Forecasting with Google Flu Trends. PLoS ONE 2013, 8, e56176. [CrossRef] [PubMed]

38. Health Map: Real-Time Sickness and Disease Reports at GermTrax. Available online: http:/ /www.germtrax. com/Map.aspx (accessed on 21 July 2017).

39. Sickweather. Available online: http:/ / www.sickweather.com/how/ (accessed on 21 July 2017).

40. CrowdMed, Online Medical Diagnosis, Differential Diagnosis. Available online: https://www.crowdmed. com/ (accessed on 21 July 2017).

41. Eger, J.M.; Maggipinto, A. Information Systems: People, Organizations, Institutions, and Technologies; Springer Science \& Business Media: Berlin, Germany, 2010; pp. 23-30.

42. Brandsen, T.; Marc, H. (Eds.) The Future of Governance; National Centre for Public Performance: Newark, NJ, USA, June 2009. 
43. Ryan, R.M.; Deci, E.L. Self-determination theory and the facilitation of intrinsic motivation, social development, and well-being. Am. Psychol. 2000, 55, 68-78. [CrossRef] [PubMed]

44. Brabham, D.C. Moving the crowd at iStockphoto: The composition of the crowd and motivations for participation in a crowdsourcing application. First Monday 2008, 13, 1-19. [CrossRef]

45. Organisciak, P. Motivation of Crowds: The Incentives That Make Crowdsourcing Work I Crowdstorming. Available online: https://crowdstorming.wordpress.com/2008/01/31/motivation-of-crowds-theincentives-that-make-crowdsourcing-work/ (accessed on 28 June 2017).

46. Brabham, D.C. Motivations for Participation in a Crowdsourcing Application to Improve Public Engagement in Transit Planning. J. Appl. Commun. Res. 2012, 40, 307-328. [CrossRef]

47. Baruch, A.; May, A.; Yu, D. The motivations, enablers and barriers for voluntary participation in an online crowdsourcing platform. Comput. Hum. Behav. 2016, 64, 923-931. [CrossRef]

48. Shao, B.; Shi, L.; Xu, B.; Liu, L. Factors affecting participation of solvers in crowdsourcing: An empirical study from China. Electron. Mark. 2012, 22, 73-82. [CrossRef]

49. Jung, J.-Y.; Qiu, J.L.; Kim, Y.C. Internet connectedness and inequality: Beyond the 'divide'. Commun. Res. 2001, 28, 507-535. [CrossRef]

50. Ulrich, K.T. Design: Creation of Artifacts in Society. SSRN Electron. J. 2011. [CrossRef]

51. Katila, R.; Ahuja, G. Something Old, Something New: A Longitudinal Study of Search Behavior And New Product Introduction. Acad. Manag. J. 2002, 45, 1183-1194.

52. Poetz, M.K.; Schreier, M. The value of crowdsourcing: Can users really compete with professionals in generating new product ideas? J. Prod. Innov. Manag. 2012, 29, 245-256. [CrossRef]

53. Brabham, D.C.; Ribisl, K.M.; Kirchner, T.R.; Bernhardt, J.M. Crowdsourcing applications for public health. Am. J. Prev. Med. 2014, 46, 179-187. [CrossRef] [PubMed]

54. Brabham, D.C. The Myth of Amateur Crowds. Inf. Commun. Soc. 2012, 15, 394-410. [CrossRef]

55. Aitamurto, T. Crowdsourcing for Democracy: A New Era in Policy-Making; SSRN: Rochester, NY, USA, 2012.

56. Campbell, H.; Marshall, R. Public Involvement and Planning: Looking beyond the One to the Many. Int. Plan. Stud. 2000, 5, 321-344. [CrossRef]

57. Trottier, D. Crowdsourcing CCTV surveillance on the Internet. Inf. Commun. Soc. 2014, 17, 609-626. [CrossRef]

58. Bertot, J.C.; Jaeger, P.T.; Grimes, J.M. Crowd-sourcing transparency: ICTs, social media, and government transparency initiatives. In Proceedings of the 11th Annual International Digital Government Research Conference on Public Administration Online: Challenges and Opportunities, Puebla, Mexico, 17 May 2010; pp. 51-58.

59. Huang, S.; Fu, W. Don't Hide in the Crowd! Increasing Social Transparency between Peer Workers Improves Crowdsourcing Outcomes. In Proceedings of the SIGCHI Conference on Human Factors in Computing Systems, Paris, France, 27 April-2 May 2013; pp. 621-630.

60. Kajino, H.; Arai, H.; Kashima, H. Preserving worker privacy in crowdsourcing. Data Min. Knowl. Discov. 2014, 28, 1314-1335. [CrossRef]

61. Yang, K.; Zhang, K.; Ren, J.; Shen, X.S. Security and privacy in mobile crowdsourcing networks: Challenges and opportunities. IEEE Commun. Mag. 2015, 53, 75-81. [CrossRef]

62. Wang, Y.; Huang, Y.; Louis, C. Towards a framework for privacy-aware mobile crowdsourcing. In Proceedings of the 2013 International Conference on Social Computing, Washington, DC, USA, 8-14 September 2013; pp. 454-459.

63. Nandan, N.; Pursche, A.; Zhe, X. Challenges in Crowdsourcing Real-Time Information for Public Transportation. In Proceedings of the 2014 IEEE 15th International Conference on Mobile Data Management (MDM), Brisbane, Australia, 15-18 July 2014; pp. 67-72.

64. Simon, P. Potholes and Big Data: Crowdsourcing Our Way to Better Government I WIRED. Available online: https://www.wired.com/insights/2014/03/potholes-big-data-crowdsourcing-waybetter-government/ (accessed on 9 July 2017).

65. Peppard, J.; Edwards, C.; Lambert, R. Crowdsourcing: How to benefit from (too) many great ideas. MIS Q. 2011, 10, 115-117.

66. Kitchin, R. The real-time city? Big data and smart urbanism. GeoJournal 2014, 79, 1-14. [CrossRef]

67. Inmon, B. Granularity of Data. Available online: http://searchdatamanagement.techtarget.com/news/ 2240034162/Granularity-of-data (accessed on 9 July 2017). 
68. Burger-Helmchen, T.; Penin, J. The limits of crowdsourcing inventive activities: What do transaction cost theory and the evolutionary theories of the firm teach us? In Proceedings of the Workshop on Open Source Innovation, Strasbourg, France, 26 March 2010; pp. 1-26.

69. Weaver, A.C.; Boyle, J.P.; Besaleva, L.I. Applications and trust issues when crowdsourcing a crisis. In Proceedings of the 21st International Conference on Computer Communications and Networks (ICCCN), Munich, Germany, 30 July-2 August 2012.

70. Riedl, C.; Blohm, I.; Leimeister, J.M.; Kremar, H. Rating Scales for Collective Intelligence in Innovation Communities: Why Quick and Easy Decision Making Does Not Get It Right; SSRN: Rochester, NY, USA, 2010.

71. Hirth, M.; Hoßfeld, T.; Tran-Gia, P. Cost-optimal validation mechanisms and cheat-detection for crowdsourcing platforms. In Proceedings of the 5th Innovative Mobile and Internet Services in Ubiquitous Computing (IMIS), Seoul, Korea, 30 June-2 July 2011; pp. 316-321.

72. Prabaker, M.; Rao, J.; Fette, I.; Kelley, P.; Cranor, L.; Hong, J. Understanding and Capturing People's Privacy Policies in a People Finder Application. Pers. Ubiquitous Comput. 2008, 13, 401-412.

73. Halder, B. Measuring Security, Privacy and Data Protection in Crowdsourcing; SSRN: Rochester, NY, USA, 2014.

74. Azevedo de Almeida, B.; Mostafavi, A. Resilience of infrastructure systems to sea-level rise in coastal areas: Impacts, adaptation measures, and implementation challenges. Sustainability 2016, 8, 1115. [CrossRef]

75. Rasoulkhani, K.; Reyes, M.P.; Mostafavi, A. Emergence of resilience from infrastructure dynamics: A simulation framework for theory building. In Proceedings of the ASCE Computing in Civil Engineering Workshop, Seattle, WA, USA, 25-27 June 2017; pp. 256-264.

(C) 2018 by the authors. Licensee MDPI, Basel, Switzerland. This article is an open access article distributed under the terms and conditions of the Creative Commons Attribution (CC BY) license (http://creativecommons.org/licenses/by/4.0/). 